Check for updates

Cite this: RSC Adv., 2020, 10, 10681

Received 8th December 2019

Accepted 25th February 2020

DOI: $10.1039 / c 9 r a 10296 e$

rsc.li/rsc-advances

\section{Synthesis of nano-octahedral MgO via a solvothermal-solid-decomposition method for the removal of methyl orange from aqueous solutions}

\author{
Xirui Yan, (DD a Zixin Tian, ${ }^{a}$ Wencai Peng, (D) *ab Jianshu Zhang, ${ }^{\text {ab }}$ Yanbin Tong, ${ }^{a}$ Jun Li, ${ }^{* c}$ \\ Dekui Sun, ${ }^{d}$ Hui Ge ${ }^{d}$ and Jinli Zhang (D) ae
}

\begin{abstract}
Nano magnesium oxide has wide applications, and $\mathrm{MgO}$ with (111) facets has wider potential applications than $\mathrm{MgO}$ with (100) facets (e.g., in catalysis and adsorption). However, nano MgO with (111) polar faces has not been studied throughly, so the preparation of nano-octahedral $\mathrm{MgO}(\mathrm{N}-\mathrm{O}-\mathrm{MgO})$ with eight exposed (111) facets remains a great challenge. Herein, we successfully synthesised $\mathrm{N}-\mathrm{O}-\mathrm{MgO}$ via an effective solvothermal-solid-decomposition method and studied its adsorption performance. The obtained $\mathrm{N}-\mathrm{O}-\mathrm{MgO}$ showed excellent performance $\left(229.36 \mathrm{mg} \mathrm{g}^{-1}\right.$ ) for methyl orange (MO). The adsorption follows the pseudo-second-order kinetic equation and the Langmuir isotherm model. The dimensionless parameter $R_{\mathrm{L}}(0.042)$ and Gibbs free energy $\Delta G\left(-6.538 \mathrm{~kJ} \mathrm{~mol}^{-1}\right)$ revealed that the adsorption of $\mathrm{MO}$ on $\mathrm{N}-\mathrm{O}-\mathrm{MgO}$ was a spontaneous and feasible process. The adsorption of $\mathrm{MO}$ and methyl blue (MB) on $\mathrm{N}-\mathrm{O}-\mathrm{MgO}$ were studied to determine the adsorption sites. Based on these experiments and analysis, it was determined that the adsorption sites were magnesium ions and the adsorption mechanism was proposed to describe the adsorption process.
\end{abstract}

\section{Introduction}

Nano metal oxide materials have attracted numerous researchers due to their unique applications in the fields of energy and environment. As an important nano metal oxide, nano magnesium oxide (nano $\mathrm{MgO}$ ) shows a wide range of applications, for e.g., as a solid-base catalyst and carrier (for Claisen-Schmidt reaction, ${ }^{1}$ the preparation of Schiff bases, ${ }^{2}$ and the loading of nickel atoms ${ }^{3}$ for $\mathrm{CO}_{2}$ reforming of methane), as an adsorbent (for the removal of organic dyes such as methyl orange, ${ }^{4}$ heavy metal ions such as cadmium ions and lead ions, ${ }^{5}$ and fluoride ions ${ }^{6}$ ), and as a template and additive (for the preparation of graphene-like materials ${ }^{7}$ and the additive of $\mathrm{CO}_{2}$ adsorbent $^{8}$ ). Nano $\mathrm{MgO}$ also shows optical properties ${ }^{9}$ and bactericidal properties. ${ }^{10}$ There are some methods used for the

${ }^{a}$ School of Chemistry and Chemical Engineering, Shihezi University, Shihezi 832003, Xinjiang, China.E-mail: pengwencai@shzu.edu.cn; junli@ipe.ac.cn

${ }^{b}$ Key Laboratory for Green Processing of Chemical Engineering of Xinjiang Bingtuan, Shihezi, Xinjiang, China

'State Key Laboratory of Multiphase Complex Systems, Institute of Process Engineering, Chinese Academy of Sciences, Beijing, 100190, China

${ }^{a}$ State Key Laboratory of Coal Conversion, Institute of Coal Chemistry, Chinese Academy of Sciences, Taiyuan, Shanxi, China

${ }^{e}$ Key Laboratory for Systems Bioengineering MOE, Tianjin University, Collaborative Innovation Centre of Chemical Science and Chemical Engineering (Tianjin), Tianjin 300072, China synthesis of nano $\mathrm{MgO}$, which include precipitation, ${ }^{\mathbf{1 1 , 1 2}}$ solid state reaction, ${ }^{13}$ microwave radiation method, ${ }^{\mathbf{1 4}}$ and sol-gel route, ${ }^{15}$ However, in these synthetic procedures, ${ }^{\mathbf{9}, 10,15}$ researchers have paid less attention to the crystal facet of nano $\mathrm{MgO} ; \mathrm{MgO}$ usually grows into a cubic structure with (100) facets. $^{16}$

In the past few years, numerous studies have focused on $\mathrm{MgO}$ with the (111) polar facet due to its higher reactivity in catalysis $^{17,18}$ and antibacterial ${ }^{19}$ applications. However, the reports about nano $\mathrm{MgO}$ with (111) polar facets and its properties are rare. Although a large MgO crystal can be mechanically cut and polished to obtain micro- or nano-scale materials, it would be difficult to control the facet that is exposed.$^{20}$ It is an effective strategy to obtain $\mathrm{MgO}$ with the polar (111) facet by wet chemistry methods, which is often necessary to use additives in the reaction system to create a polar environment and to inhibit the rapid disappearance of the polar surface during the reaction. Ryan Richard et al. ${ }^{17}$ synthesised $\mathrm{MgO}$ (111) nanoplates by adding 4-methoxybenzyl alcohol in the reaction system, which has a strong interaction with the inorganic intermediate $\mathrm{Mg}(\mathrm{OH})-\left(\mathrm{OCH}_{3}\right)$. Jupille et al. ${ }^{21}$ obtained (111) facets via etching of cubic MgO smoke crystals using neutral water in wet conditions, which had an average particle size of $170 \mathrm{~nm}$ and a specific surface area of $5.5 \mathrm{~m}^{2} \mathrm{~g}^{-1}$. Hao et al. ${ }^{19}$ obtained $\mathrm{MgO}$ with (111) facets exposed via the solution combustion process of the mixture of magnesium nitrate and urea. Xie et al. ${ }^{\mathbf{1 6 , 2 0}}$ 
prepared micro-scale octahedral MgO with $2.4 \mathrm{~m}^{2} \mathrm{~g}^{-1}$ specific surface area by decomposing magnesium nitrate in molten lithium nitrate at $400{ }^{\circ} \mathrm{C}$. Further studies by Jeffrey D. Rimer ${ }^{22}$ discussed the influence of different factors on the morphology of $\mathrm{MgO}$ and demonstrated that the molten salt systems contributed to the formation of (111) facets in the decomposition of magnesium salts. For the molten salt systems, the crystal formed by the free movement of ions must grow to the microscale to reduce surface energy and maintain self-stability. Thus, the synthesis of nano-octahedral MgO with eight (111) facets exposed remains a huge challenge.

In this work, we first successfully prepared nano-scale octahedral MgO with eight (111) facets exposed via an effective solvothermal-solid-decomposition method and evaluated its adsorption performance using MO. The adsorption characteristics and mechanism were studied by a series of experiments and calculations, which included the simulation of different kinetic and isotherm model, and the determination of relevant thermodynamic parameters. Based on these analyses, the adsorption sites were determined and an adsorption mechanism for MO adsorption on $\mathrm{N}-\mathrm{O}-\mathrm{MgO}$ was proposed. These studies should be a useful reference for the preparation of materials and the exploration of adsorption mechanisms as well as for the preparation of nano materials with polar facets, the characteristics of nano materials with polar facet, and the exploration of adsorption mechanisms.

\section{Experimental}

\subsection{Preparation of N-O-MgO}

Magnesium nitrate $\left(\mathrm{Mg}\left(\mathrm{NO}_{3}\right)_{2} \cdot 6 \mathrm{H}_{2} \mathrm{O}, \mathrm{AR}\right)$; urea (AR) and ethanol (AR); methyl orange (MO) and methyl blue (MB) were purchased from Aladdin Co., Ltd; Tianjin Chemical Reagent Manufacturing Co., Ltd; Adamas Reagent Co., Ltd, respectively. All of them were used without further purification.

$\mathrm{N}-\mathrm{O}-\mathrm{MgO}$ was prepared via a solvothermal-soliddecomposition method. In a typical route, $2.56 \mathrm{~g}$ of $\mathrm{Mg}\left(\mathrm{NO}_{3}\right)_{2}$ $\cdot 6 \mathrm{H}_{2} \mathrm{O}$ was dissolved in $50 \mathrm{~mL}$ of ethanol and the homogeneous solution was transferred into a $100 \mathrm{~mL}$ Teflon bottle. Then, the mixture was thoroughly stirred after adding $6.00 \mathrm{~g}$ of urea into the solution. Subsequently, the Teflon bottle was placed in a stainless-steel vessel that was sealed and put into a temperature-controlled oven for solvothermal treatment at $200{ }^{\circ} \mathrm{C}$ for $24 \mathrm{~h}$. After the heat treatment, fresh precipitates were collected, washed, and dried at $80{ }^{\circ} \mathrm{C}$ in air. $\mathrm{N}-\mathrm{O}-\mathrm{MgO}$ was produced by calcining the precipitates at $500{ }^{\circ} \mathrm{C}$ and continuing for $5 \mathrm{~h}$.

\subsection{Characterisation}

The crystal structures of the obtained samples were examined by X-ray diffraction (XRD) on a D8 Advance X-ray diffractometer (Germany) using $\mathrm{Cu} \mathrm{K} \alpha$ radiation.

The microscopic morphology of $\mathrm{MgO}$ was analysed by scanning electron microscopy (SEM) on a Hitachi S-4100 FESEM instrument (Japan) at $10 \mathrm{kV}$ and transmission electron microscopy (TEM) on a Tecnai G2 F20 field emission transmission electron microscope (USA) at $200 \mathrm{kV}$.
$\mathrm{N}_{2}$ adsorption/desorption isotherm was recorded on a Micromeritics ASAP 2020 apparatus (USA) at $77 \mathrm{~K}$ for calculating the specific surface area and pore size distribution by the Brunauer-Emmett-Teller (BET) and Barrett-Joyner-Halenda (BJH) methods, respectively.

The vibrational characteristics of the obtained samples were recorded by a Fourier transform spectrometer (FT-IR; Agilent Cary 630, Agilent, America) in pressed $\mathrm{KBr}$ pellets.

The X-ray photoelectron spectrum (XPS) of N-O-MgO was obtained on a Kratos AMICUS spectrometer (SHIMADZU, JP) using $\mathrm{Al} \mathrm{K} \alpha$ radiation. The binding energy of $\mathrm{O}$ element was calibrated relative to the carbon impurity with $\mathrm{C} 1 \mathrm{~s}$ at $285 \mathrm{eV}$.

The concentrations of $\mathrm{MO}$ and $\mathrm{MB}$ in the aqueous solutions were measured using a Shimadzu UV-2550 UV-visible spectrometer (Japan).

\subsection{Adsorption experiments}

The batch adsorption experiments were carried out by mixing $\mathrm{N}-\mathrm{O}-\mathrm{MgO}$ particles with $20 \mathrm{~mL}$ aqueous MO solution under stirring at $\mathrm{pH} 6.0$ and $303 \mathrm{~K}$ temperature at the rate of 150 $\mathrm{rpm} \min ^{-1}$. The three parameters were changed during the experiments: adsorbent amount $\left(0.5-1.75 \mathrm{~g} \mathrm{~L}^{-1}\right)$, contact time (5-150 min), and MO concentration (20-200 $\left.\mathrm{mg} \mathrm{L}^{-1}\right)$. After the experiments, the mixture was separated and the ultimate concentration of MO was determined.

The adsorption capacity of MO on $\mathrm{N}-\mathrm{O}-\mathrm{MgO}$ and the removal ratio of MO were calculated using eqn (1) and (2).

$$
\begin{gathered}
q_{\mathrm{e}}=\left(C_{0}-C_{\mathrm{e}}\right) V / m \\
\eta=100 \%\left(C_{0}-C_{\mathrm{e}}\right) / C_{0}
\end{gathered}
$$

In which $q_{\mathrm{e}}\left(\mathrm{mg} \mathrm{g}^{-1}\right)$ is the adsorption capacity of $\mathrm{MO}$ on $\mathrm{N}$ $\mathrm{O}-\mathrm{MgO}, \eta(\%)$ represents the MO removal efficiency, $C_{0}\left(\mathrm{mg} \mathrm{L}^{-1}\right)$ is the MO initial concentration, $C_{\mathrm{e}}\left(\mathrm{mg} \mathrm{L}^{-1}\right)$ is the adsorption equilibrium concentration of $\mathrm{MO}, V(\mathrm{~L})$ is the $\mathrm{MO}$ solution volume, and $m(\mathrm{~g})$ is the weight of $\mathrm{N}-\mathrm{O}-\mathrm{MgO}$ particles.

The pseudo-first-order and pseudo-second-order (eqn (3) and (4)) kinetic models were simulated to describe the adsorption process of $\mathrm{MO}$ on $\mathrm{N}-\mathrm{O}-\mathrm{MgO}$.

$$
\begin{gathered}
\ln \left(q_{\mathrm{e}}-q_{t}\right)=\ln q_{\mathrm{e}}-K_{1} t \\
t / q_{t}=1 /\left(K_{2} q_{\mathrm{e}}^{2}\right)+t / q_{\mathrm{e}}
\end{gathered}
$$

where $q_{\mathrm{e}}$ and $q_{t}\left(\mathrm{mg} \mathrm{g}^{-1}\right)$ are the adsorption capacities of MO adsorbed on $\mathrm{N}-\mathrm{O}-\mathrm{MgO}$ at the equilibrium time and at a specific time $t(\mathrm{~min}), K_{1}\left(\mathrm{~min}^{-1}\right)$ is the pseudo-first-order model rate constant, and $K_{2}\left(\mathrm{~g} \mathrm{mg}^{-1} \mathrm{~min}^{-1}\right)$ is the pseudo-second-order model rate constant.

The adsorption process of MO on the N-O-MgO particles was also simulated based on the Langmuir isotherm and Freundlich isotherm (eqn (5) and (6)). The dimensionless separation factor constant $\left(R_{\mathrm{L}}\right.$, eqn (7)) was calculated to indicate the type of adsorption.

$$
q_{\mathrm{e}}=q_{\mathrm{m}} K_{\mathrm{L}} C_{\mathrm{e}} /\left(1+K_{\mathrm{L}} C_{\mathrm{e}}\right)
$$




$$
\begin{gathered}
q_{\mathrm{e}}=K_{\mathrm{F}} C_{\mathrm{e}}^{1 / n} \\
R_{\mathrm{L}}=1 /\left(1+K_{\mathrm{L}} C_{0}\right)
\end{gathered}
$$

where $K_{\mathrm{L}}\left(\mathrm{L} \mathrm{mg}^{-1}\right)$ is the Langmuir constant, $C_{\mathrm{e}}\left(\mathrm{mg} \mathrm{L}^{-1}\right)$ is the adsorption equilibrium concentration of $\mathrm{MO}, q_{\mathrm{e}}\left(\mathrm{mg} \mathrm{g}^{-1}\right)$ is the adsorbed amount of $\mathrm{MO}$ on $\mathrm{N}-\mathrm{O}-\mathrm{MgO}$ at adsorption equilibrium, $q_{\mathrm{m}}\left(\mathrm{mg} \mathrm{g}^{-1}\right)$ represents the maximum theoretical adsorption capacity, $K_{\mathrm{F}}\left(\mathrm{mg} \mathrm{g}^{-1}\right)\left(\mathrm{L} \mathrm{mg}^{-1}\right)^{1 / n}$ is the Freundlich constant and $n$ is the adsorption intensity. $R_{\mathrm{L}}>1, R_{\mathrm{L}}=1,0<R_{\mathrm{L}}<$ 1 , and $R_{\mathrm{L}}=0$ indicate that the adsorption process is unfavourable, linear, favourable, and irreversible, respectively.

\section{Results and discussion}

\subsection{Characterization of N-O-MgO}

In this ethanol solvent system, urea molecules were a more advantageous ligand than water molecules for magnesium ions, which may inhibit the growth rate of $\mathrm{MgO}$ (111) facet and lead to octahedral growth under the decomposition process. Fig. 1(A) shows the XRD pattern of the products, where all the diffraction peaks agreed with the rock-salt structure MgO (JCPDS no. 450946), so the products were $\mathrm{MgO}$. As seen in Fig. 1(B), the
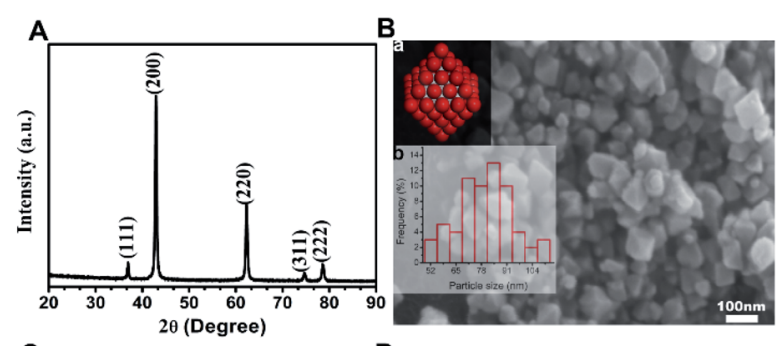

C

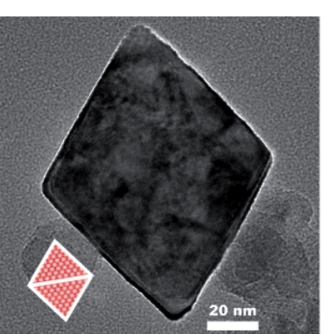

D
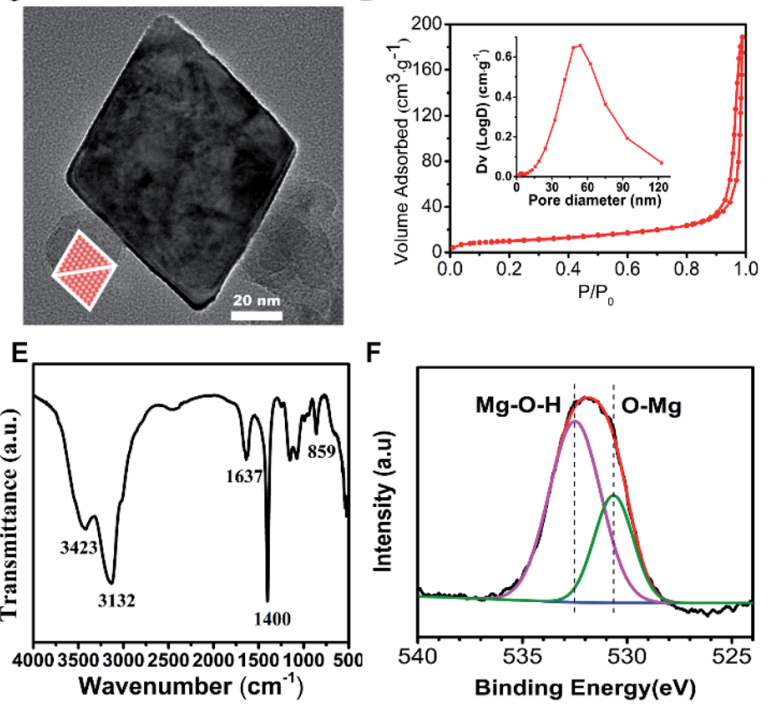

Fig. 1 Characterisation of the synthesized MgO: (A) XRD pattern; (B) SEM image and corresponding ( $a$, inset) model diagram of octahedral $\mathrm{MgO}$ and (b, inset) histogram of particle size distribution; (C) TEM image and model projected along the same crystal axis direction (inset); (D) $\mathrm{N}_{2}$ adsorption/desorption isotherm and pore size distribution (inset) of $\mathrm{N}-\mathrm{O}-\mathrm{MgO}$. (E) FT-IR pattern; (F) O 1s XPS of $\mathrm{N}-\mathrm{O}-\mathrm{MgO}$. morphology of the products (MgO) was octahedral with an average particle size of $79.83 \mathrm{~nm}$. This corresponded to the schematic model of rock-salt $\mathrm{MgO}$ with eight polar (111) facets exposed (inset a) and the histogram of particle size distribution is shown (inset b). TEM was carried out to characterize the exposed facets of the MgO octahedral. Fig. 1(C) presents the TEM image along the [110] zone axis, in which the octahedron $\mathrm{MgO}$ appeared to be a diamond. The diamond model (inset) was drawn by projecting the octahedron along the [110] direction, which was in good agreement with the TEM image. These analyses proved that the as-prepared $\mathrm{MgO}$ was nano-octahedral with eight exposed (111) polar facets. The $\mathrm{N}_{2}$ adsorption/ desorption isotherm and pore size distribution curve (inset) of $\mathrm{N}-\mathrm{O}-\mathrm{MgO}$ are shown in Fig. 1(D). The $\mathrm{N}-\mathrm{O}-\mathrm{MgO}$ isotherm showed type-IV characteristics with a significant H3 loop. The formation of pores in $\mathrm{N}-\mathrm{O}-\mathrm{MgO}$ was a result of the aggregation of the particles. The BET specific surface area was $36.84 \mathrm{~m}^{2} \mathrm{~g}^{-1}$, which was higher than that of micro-scale octahedral MgO (2.4 $\left.\mathrm{m}^{2} \mathrm{~g}^{-1}\right) .{ }^{16}$ Fig. 1(E) shows the FT-IR pattern of N-O-MgO. The broad bands located at $3420 \mathrm{~cm}^{-1}$ and $1637 \mathrm{~cm}^{-1}$ correspond to water molecules or hydroxyl groups. ${ }^{23}$ The peak located at $3132 \mathrm{~cm}^{-1}$ may result from the hydrogen bonds. The peaks at $1400 \mathrm{~cm}^{-1}$ and $859 \mathrm{~cm}^{-1}$ were assigned to magnesium-oxygen $(\mathrm{Mg}-\mathrm{O})$ group or magnesium-hydroxyl $(\mathrm{Mg}-\mathrm{OH})$ group. ${ }^{24}$ The FT-IR spectrum revealed abundant hydroxyl groups on $\mathrm{N}-\mathrm{O}-$ $\mathrm{MgO}$ surfaces. The $\mathrm{O}$ element of $\mathrm{N}-\mathrm{O}-\mathrm{MgO}$ was investigated by $\mathrm{X}$-ray photoelectron spectroscopy. The O 1s XPS is shown in Fig. 1(F), in which the $\mathrm{O} 1 \mathrm{~s}$ spectrum is divided into two peaks. The binding energies of 530 and $532 \mathrm{eV}$ corresponded to the lattice oxygen ${ }^{25}(\mathrm{Mg}-\mathrm{O})$ and magnesium hydroxyl group $(\mathrm{Mg}-\mathrm{O}-$ $\mathrm{H})$, respectively. The result also indicated abundant hydroxyl groups on $\mathrm{N}-\mathrm{O}-\mathrm{MgO}$ surfaces, which was in accordance with the FT-IR analysis.

\subsection{Adsorption experiment}

3.2.1 Effect of adsorbent amount. As an important parameter, adsorbent amount was investigated for the removal of MO under equilibrium conditions, as shown in Fig. 2(A). As $\mathrm{N}-\mathrm{O}-\mathrm{MgO}$ concentration increased from 0.5 to $1.75 \mathrm{~g} \mathrm{~L}^{-1}$, its adsorption capacity gradually decreased from 176.30 to $56.28 \mathrm{mg} \mathrm{g}^{-1}$, likely due to decrease in the utilisation rate of the adsorption sites on increasing the amount of $\mathrm{N}-\mathrm{O}-\mathrm{MgO}{ }^{26}$

The initial removal percentage was over $81.85 \%$ and reached 99.89\% when the adsorbent amount was $0.75 \mathrm{~g} \mathrm{~L}^{-1}$; then, the removal rate increased slowly. This was explained by the increase in adsorption sites for higher N-O-MgO amounts, leading to the increase in removal rate. ${ }^{27}$

3.2.2 Effect of contact time and adsorption kinetics. The contact time remarkably influenced the adsorption of MO on N$\mathrm{O}-\mathrm{MgO}$, as shown in Fig. 2(B). For the adsorption of MO on N-O$\mathrm{MgO}$, the adsorption was fast in the first $5 \mathrm{~min}$, implying that $\mathrm{N}$ $\mathrm{O}-\mathrm{MgO}$ could rapidly adsorb MO molecules from the aqueous solution; the adsorption equilibrium was reached after $60 \mathrm{~min}$, where the adsorption amount was $119.42 \mathrm{mg} \mathrm{g}^{-1}$.

The adsorption kinetic behaviour of $\mathrm{MO}$ on $\mathrm{N}-\mathrm{O}-\mathrm{MgO}$ was simulated using pseudo-first-order and pseudo-second-order 

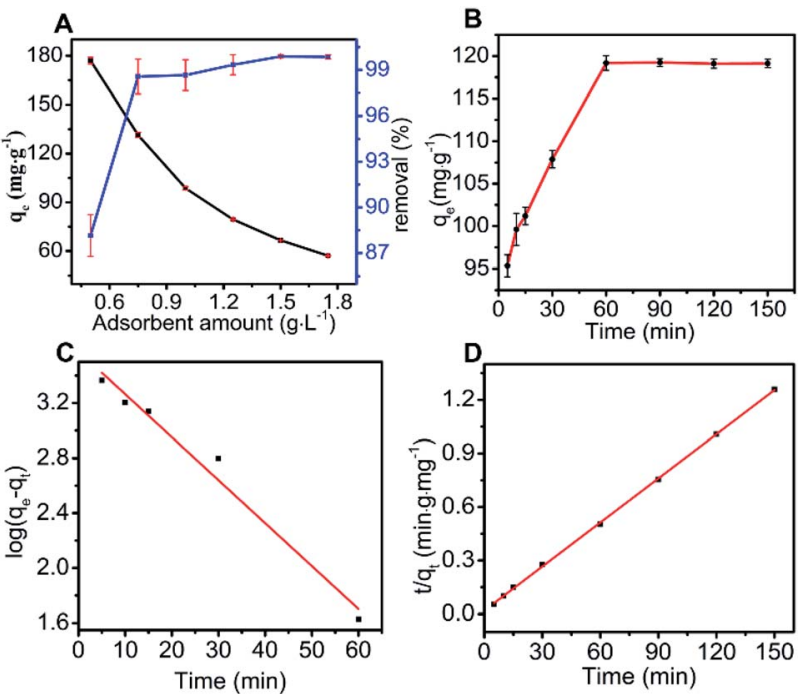

Fig. 2 Effect of (A) adsorbent amount and (B) contact time (adsorbent amount $=0.75 \mathrm{~g} \mathrm{~L}^{-1}, \mathrm{pH}=6, T=303 \mathrm{~K}, t=150 \mathrm{~min}$ ) on the removal of $\mathrm{MO}$ by $\mathrm{N}-\mathrm{O}-\mathrm{MgO}$. Derived (C) pseudo-first and (D) pseudo-secondorder kinetic models.

kinetic models. The fitting results and relevant parameters are shown in Fig. 2(C), (D) and Table 1, respectively. Compared to the simulation by pseudo-first-order model, the calculation results using the pseudo-second-order model were closer to the experimental data and its correlation coefficient $R^{2}$ was higher than 0.999. This indicated that the adsorption of MO on N-O$\mathrm{MgO}$ can be more adequately described by the pseudo-secondorder kinetic model. For this adsorption process, the overall adsorption rate of $\mathrm{MO}$ was controlled by the chemical process through ion exchange between $\mathrm{MO}$ and $\mathrm{N}-\mathrm{O}-\mathrm{MgO}{ }^{28} \mathrm{~A}$ detailed explanation of the adsorption process is provided in Section 3.3.

3.2.3 Effect of $\mathbf{~ p H}$. The effect of $\mathrm{pH}$ in the range from 2 to 12 on the adsorption of $\mathrm{MO}$ on N-O-MgO is shown in Fig. 3(A). The $\mathrm{pH}$ was adjusted with $0.1 \mathrm{M} \mathrm{HCl}$ and $0.1 \mathrm{M} \mathrm{NaOH}$ solutions, and the $\mathrm{pH}$ of each solution was measured by using a laboratory scale $\mathrm{pH}$ meter (PHS-25). As the $\mathrm{pH}$ increased from 2 to 6 , the adsorption capacity of N-O-MgO slowly increased from 120 to 124 , and the highest adsorption capacity was obtained at $\mathrm{pH}=$ 6. As the pH increased from 6 to 12 , the adsorption capacity of $\mathrm{N}-\mathrm{O}-\mathrm{MgO}$ evidently decreased. With the increase in the concentration of $\mathrm{H}^{+}$, the inhibition of electrostatic interaction between the $-\mathrm{SO}_{3}{ }^{-}$groups of $\mathrm{MO}$ and the positive charge of the $\mathrm{N}-\mathrm{O}-\mathrm{MgO}$ surface was weak. With the increase in the concentration of $\mathrm{OH}^{-}$, it competed with the $-\mathrm{SO}_{3}{ }^{-}$groups of $\mathrm{MO}$ for the adsorption sites on the adsorbent surface. ${ }^{29,30}$ The analysis
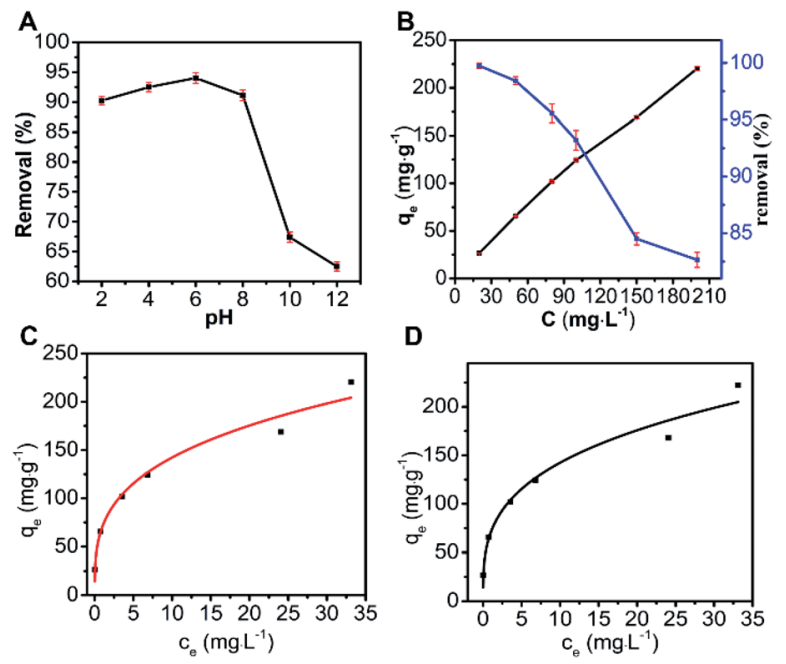

D

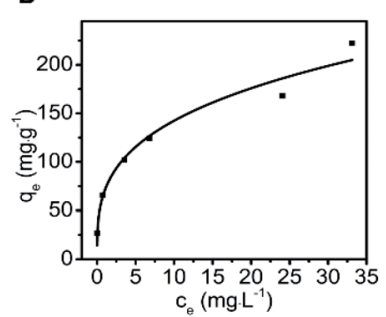

Fig. 3 Effect of (A) $\mathrm{pH}$ and (B) $\mathrm{MO}$ concentration (adsorbent amount = $0.75 \mathrm{~g} \mathrm{~L}^{-1}, \mathrm{pH}=6, T=303 \mathrm{~K}, t=150 \mathrm{~min}$ ) on the removal of $\mathrm{MO}$ by $\mathrm{N}$ $\mathrm{O}-\mathrm{MgO}$; (C) Langmuir isotherm; (D) Freundlich isotherm.

indicated that the electrostatic interaction might be the adsorption mechanism for MO adsorption on N-O-MgO.

3.2.4 Effect of MO concentration and adsorption isotherms. The effect of $\mathrm{MO}$ concentration on its adsorption on $\mathrm{N}-\mathrm{O}-\mathrm{MgO}$ was investigated, as shown in Fig. 3(B). As the concentration increased from 20 to $200 \mathrm{mg} \mathrm{L}^{-1}$, the adsorption capacity of $\mathrm{N}-\mathrm{O}-\mathrm{MgO}$ gradually increased. This indicated that $\mathrm{N}-$ $\mathrm{O}-\mathrm{MgO}$ had good adsorption performance for MO molecules in aqueous solution.

The fitting result and relevant parameters for MO adsorption using the Langmuir and Freundlich isotherm models are presented in Fig. 3(C), (D) and Table 2, respectively. According to the fitting result, the adsorption parameters fitted well with both the Langmuir isotherm $\left(R^{2}=0.9520\right)$ and Freundlich isotherm $\left(R^{2}=0.9594\right)$. Here, we used the Langmuir isotherm model to describe the adsorption process for MO. For the Langmuir isotherm model, the adsorption of $\mathrm{MO}$ on $\mathrm{N}-\mathrm{O}-\mathrm{MgO}$ was monolayer. The $R_{\mathrm{L}}$ value was 0.042 by calculation, implying favourable adsorption of $\mathrm{MO}$ on $\mathrm{N}-\mathrm{O}-\mathrm{MgO}$.

3.2.5 Recyclability. The reusability of an adsorbent is essential for its practical application. The results of N-O-MgO regeneration are shown in Fig. 4(A). The removal rate of the adsorbent after two cycles was still over $94 \%$. The results implied that N-O-MgO was an efficient adsorbent with excellent reusability. Moreover, the regeneration of $\mathrm{N}-\mathrm{O}-\mathrm{MgO}$ was achieved through simple calcination for $3 \mathrm{~h}$ at $500{ }^{\circ} \mathrm{C}$ after separation.

Table 1 Kinetic parameters for the adsorption of $\mathrm{MO}$ on $\mathrm{N}-\mathrm{O}-\mathrm{MgO}$

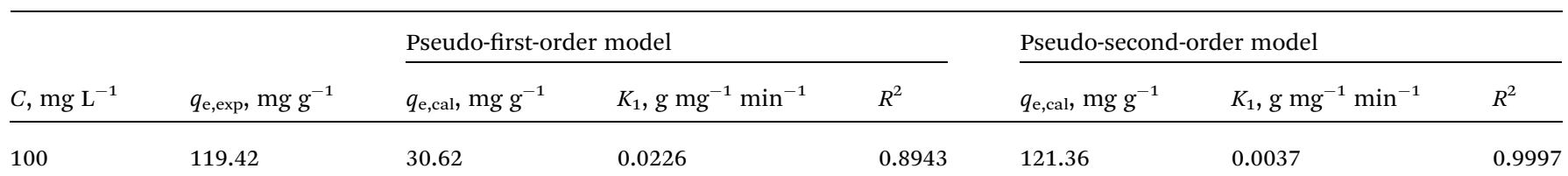


(1) The distance ( $d$, eqn (8)) between two oxygen ions and the area $\left(S_{2}\right.$, eqn (9)) of a diamond composed by four adjacent oxygen ions on the surface of $\mathrm{N}-\mathrm{O}-\mathrm{MgO}$ were calculated based on rock-salt contracture.

$$
\begin{gathered}
2 a^{2}=(2 d)^{2} \\
S_{2}=d^{2} \sqrt{ } 3 / 2
\end{gathered}
$$

(2) Number of atoms forming a diamond ( $n$, eqn (10)):

$$
n=2 / 6+2 / 3=1
$$

(3) Calculation of the utilisation ratio (eqn (11)-(13)) of the $\mathrm{N}$ $\mathrm{O}-\mathrm{MgO}$ adsorption sites.

The amount of outmost layer oxygen ions on the $\mathrm{N}-\mathrm{O}-\mathrm{MgO}$ (111) facet:

$$
N_{1}=S_{1} / S_{2}
$$

The number of MO molecules adsorbed on N-O-MgO:

$$
N_{2}=\left(q_{\mathrm{e}} A_{\mathrm{a}}\right) / M
$$

The utilisation ratio of adsorption sites:

$$
R=N_{2} / N_{1}
$$

In which $a(0.4211 \mathrm{~nm})$ is the cell constant, $d(\mathrm{~nm})$ is the distance between two magnesium on the (111) facet, $S_{2}\left(\mathrm{~nm}^{2}\right)$ is the area of a diamond composed by four adjacent $\mathrm{Mg}$ atoms on the (111) facet, $S_{1}\left(36.84 \mathrm{~m}^{2}\right)$ is the specific surface area of a unit mass of $\mathrm{N}-\mathrm{O}-\mathrm{MgO}$ particles, $N_{1}$ is the amount of outmost layer $\mathrm{O}$ ions on $\mathrm{N}-\mathrm{O}-\mathrm{MgO}$ per unit mass, $\mathrm{N}_{2}$ is the adsorption number of MO molecules on $\mathrm{N}-\mathrm{O}-\mathrm{MgO}, R$ is the utilisation ratio of adsorption sites on $\mathrm{N}-\mathrm{O}-\mathrm{MgO}, q_{\mathrm{e}}\left(\mathrm{mg} \mathrm{g}^{-1}\right)$ is the amount of adsorbed MO molecules on the adsorbent surface at equilibrium, $A_{\mathrm{a}}\left(6.022 \times 10^{23} \mathrm{~mol}^{-1}\right)$ is the Avogadro's constant, and $M$ (327.36 $\left.\mathrm{g} \mathrm{mol}^{-1}\right)$ is the molar mass of MO.

The calculations indicate that the utilisation ratio of the adsorption sites on $\mathrm{N}-\mathrm{O}-\mathrm{MgO}$ was $91.70 \%$, indicating that $\mathrm{MO}$ molecules effectively formed a monolayer on N-O-MgO.

3.3.3 Adsorption mechanism. An equation for $\mathrm{MO}$ adsorption on $\mathrm{N}-\mathrm{O}-\mathrm{MgO}$ was proposed, which is eqn (14). To evaluate such a process, the thermodynamic parameters Gibbs free energy was calculated at $303 \mathrm{~K}$. The distribution coefficient $(K)$ and Gibbs free energy $(\Delta G)$ were determined using eqn (15) and (16).

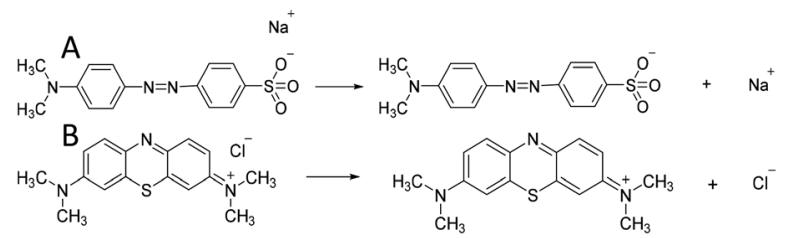

Scheme 1 lonisation equations of (A) $M O$ and (B) MB in aqueous solution.
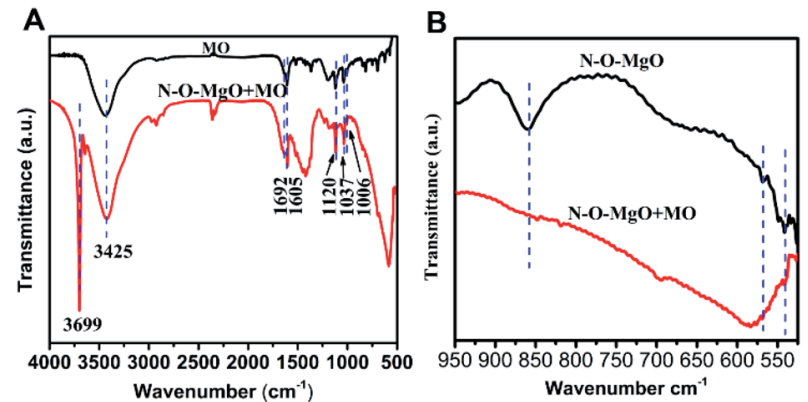

Fig. 5 (A) The FT-IR spectra of $\mathrm{MO}$ and $\mathrm{N}-\mathrm{O}-\mathrm{MgO}$ after $\mathrm{MO}$ adsorption; (B) the FT-IR spectra of $\mathrm{N}-\mathrm{O}-\mathrm{MgO}$ before and after $\mathrm{MO}$ adsorption at $525-950 \mathrm{~cm}^{-1}$.

$\mathrm{NaOH}$

$$
\text { Dye- } \mathrm{SO}_{3} \mathrm{Na}+\mathrm{N}-\mathrm{O}-\mathrm{MgO} \rightarrow \text { dye-SO }{ }_{3}-\mathrm{Mg}-\mathrm{MgO}-\mathrm{O}-\mathrm{N}+
$$

$$
K=\left(C_{0}-C_{\mathrm{e}}\right) / C_{0}
$$

$$
\Delta G=-R T \ln K
$$

In which $C_{0}\left(\mathrm{mg} \mathrm{L}^{-1}\right), C_{\mathrm{e}}\left(\mathrm{mg} \mathrm{L}^{-1}\right), R\left(8.314 \mathrm{~J} \mathrm{~mol}^{-1} \mathrm{~K}^{-1}\right)$, and $T(303 \mathrm{~K})$ are the initial concentration of $\mathrm{MO}$, equilibrium concentration of MO, gas constant, and absolute temperature, respectively.

$\Delta G$ was calculated as $-6.538 \mathrm{~kJ} \mathrm{~mol}^{-1}$, demonstrating that the adsorption process of $\mathrm{MO}$ on $\mathrm{N}-\mathrm{O}-\mathrm{MgO}$ is spontaneous and feasible, which is in accordance with the analysis of the Langmuir isotherm model.

In order to further describe the adsorption process, MO and $\mathrm{N}-\mathrm{O}-\mathrm{MgO}$ after $\mathrm{MO}$ adsorption were characterized by FT-IR spectroscopy. Fig. 5(A) shows the FTIR spectra of MO and NO-MgO after MO adsorption. The FT-IR spectra peaks located at $1605 \mathrm{~cm}^{-1}, 1120 \mathrm{~cm}^{-1}, 1692 \mathrm{~cm}^{-1}$ and $1037 \mathrm{~cm}^{-1}$, and $1006 \mathrm{~cm}^{-1}$ were attributed to phenyl groups, ${ }^{30} \mathrm{C}-\mathrm{N}$ group, ${ }^{34}$ and sulfonic acid group $\left(-\mathrm{SO}_{3}{ }^{-}\right),{ }^{35}$ and $\mathrm{C}-\mathrm{H}$ in-plane of benzene rings with bending vibration, respectively. The presence of FTIR peaks of $\mathrm{MO}$ on $\mathrm{N}-\mathrm{O}-\mathrm{MgO}$ after $\mathrm{MO}$ adsorption confirmed that the MO molecules were adsorbed on the surface of $\mathrm{N}-\mathrm{O}$ $\mathrm{MgO}$. The peaks located at $3699 \mathrm{~cm}^{-1}$ and at $3425 \mathrm{~cm}^{-1}$ were attributed to the stretching of free- and associated-hydroxyl groups, which may be caused by the formation of magnesium hydroxide $\left(\mathrm{Mg}(\mathrm{OH})_{2}\right)$ and physiosorbed water ${ }^{36}$ on the surface of $\mathrm{N}-\mathrm{O}-\mathrm{MgO}$ in the adsorption process. Compared with the FT-IR spectra of $\mathrm{N}-\mathrm{O}-\mathrm{MgO}$ shown in Fig. 1(E), the strength of hydroxyl group peaks of $\mathrm{N}-\mathrm{O}-\mathrm{MgO}$ after $\mathrm{MO}$ adsorption became weak, indicating that $-\mathrm{SO}_{3}{ }^{-}$groups of $\mathrm{MO}$ were substituted with the hydroxyl groups in the MO adsorption process. ${ }^{30,37}$ The FTIR spectra of $\mathrm{N}-\mathrm{O}-\mathrm{MgO}$ before and after $\mathrm{MO}$ adsorption at 525-950 $\mathrm{cm}^{-1}$ were shown in Fig. 5(B). The peaks of $\mathrm{Mg}-\mathrm{O}-\mathrm{Mg}$ and $\mathrm{O}-\mathrm{Mg}-\mathrm{O}$ (fingerprint area) of $\mathrm{N}-\mathrm{O}-\mathrm{MgO}$ after $\mathrm{MO}$ adsorption disappeared or shifted, further confirming that the $-\mathrm{SO}_{3}{ }^{-}$ groups of $\mathrm{MO}$ were connected with $\mathrm{Mg}^{2+}$ of the $\mathrm{N}-\mathrm{O}-\mathrm{MgO}$ surface. ${ }^{30,38}$

Based on these analyses above, the adsorption mechanism was proposed in Scheme 2. As shown in Scheme 1(A), the 


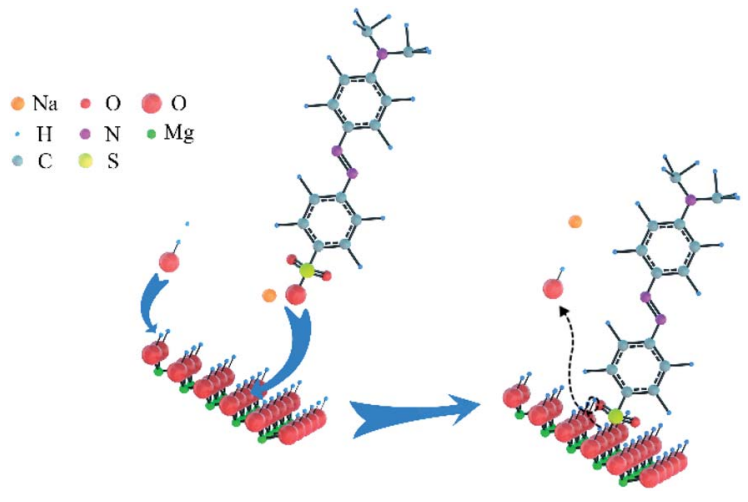

Scheme 2 Adsorption mechanism of $\mathrm{MO}$ on $\mathrm{N}-\mathrm{O}-\mathrm{MgO}$. Ionic radius of oxygen is larger than the covalent radius of oxygen. The balls of $\mathrm{Na}$ and $\mathrm{Mg}$ are ionic radius. The balls of $\mathrm{H}, \mathrm{N}, \mathrm{C}$, and $\mathrm{S}$ are the covalent radius.

exposed $-\mathrm{SO}_{3}{ }^{-}$groups of $\mathrm{MO}$ and sodium ions were formed via the ionisation of MO molecules in aqueous solution. For the adsorption process, a coordination hydroxyl group of a magnesium ion broke away from its original position and left a vacancy to form $\mathrm{OH}^{-}$in the aqueous solution; then, a $-\mathrm{SO}_{3}{ }^{-}$ group of MO with negative charge exchanged into the vacancy and bonded the magnesium ion by ion exchange and electrostatic interaction. As given in the analysis in Section 3.3.2, the utilisation ratio of adsorption sites on $\mathrm{N}-\mathrm{O}-\mathrm{MgO}$ reached $91.70 \%$, indicating that the exchange of hydroxyls and $-\mathrm{SO}_{3}{ }^{-}$ groups of $\mathrm{MO}$ were ongoing until the adsorption of MO molecules on $\mathrm{N}-\mathrm{O}-\mathrm{MgO}$ formed a monolayer.

\section{Conclusions}

In summary, we have obtained N-O-MgO particles via an effective solvothermal-solid-decomposition method and used it as an adsorbent for MO adsorption to study its adsorption performance. The adsorption process of $\mathrm{MO}$ on $\mathrm{N}-\mathrm{O}-\mathrm{MgO}$ in aqueous solution was systematically studied under different experimental conditions (adsorbent amount, contact time, MO concentration, and $\mathrm{pH}$ ). The results revealed that the pseudosecond-order kinetic model and monolayer adsorption precisely described the spontaneous and feasible adsorption process, which was analysed by the $R_{\mathrm{L}}$ and thermodynamic analyses. N-O-MgO had excellent recyclability and higher activity than N-C-MgO and MP-MgO with (100) facets exposed. The adsorption sites were identified as magnesium ions that were effectively utilised on the adsorption process. A possible adsorption mechanism was proposed based on the analysis of experiments, calculation, and characterization. The results of this study may be a reference for the preparation of nanomaterials with polar facets and adsorption mechanism with, for example, different $\mathrm{MgO}$ morphologies or even different materials.

\section{Conflicts of interest}

There are no conflicts to declare.

\section{Acknowledgements}

The works were supported by the National Natural Science Foundation of China (NSFC Grant No. 21968029), the Major Science and Technology Project of Xinjiang Bingtuan (2017AA007), the Applied Basic Research Program of Xinjiang Bingtuan (2015AG400) and Science \&Technology Research and Achievement Transformation Project of Xinjiang Bingtuan (2015AD027).

\section{References}

1 B. M. Choudary, M. L. Kantam, K. V. Ranganath, K. Mahendar and B. Sreedhar, J. Am. Chem. Soc., 2004, 126, 3396-3397.

2 H. Naeimi, K. Rabiei and Z. Rashid, Curr. Org. Chem., 2016, 20, 316-323.

3 B.-Q. Xu, J.-M. Wei, H.-Y. Wang, K.-Q. Sun and Q.-M. Zhu, Catal. Today, 2001, 68, 217-225.

4 M. R. Rezaii Mofrad, G. Mostafaii, R. Nemati, H. Akbari and N. Hakimi, Desalin. Water Treat., 2016, 57, 8330-8335.

5 Y. Cai, C. Li, D. Wu, W. Wang, F. Tan, X. Wang, P. K. Wong and X. Qiao, Chem. Eng. J., 2017, 312, 158-166.

6 R. R. Devi, I. M. Umlong, P. K. Raul, B. Das, S. Banerjee and L. Singh, J. Exp. Nanosci., 2014, 9, 512-524.

7 X. He, H. Zhang, H. Zhang, X. Li, N. Xiao and J. Qiu, J. Mater. Chem. A, 2014, 2, 19633-19640.

8 P. Lan and S. Wu, Chem. Eng. Technol., 2014, 37, 580-586.

9 R. Halder and S. Bandyopadhyay, J. Alloys Compd., 2017, 693, 534-542.

10 L. Huang, D.-Q. Li, Y.-J. Lin, M. Wei, D. G. Evans and X. Duan, J. Inorg. Biochem., 2005, 99, 986-993.

11 H.-X. Wang, B.-Y. Hu, L.-S. Wang and G.-D. Yang, Chin. J. Inorg. Chem., 2006, 22, 363-366.

12 Y. Jin, X. Pan, R. Dai, Q. Zhang, N. Zhao and J. Zong, Inorg. Chem. Ind., 2014, 46, 33-35.

13 H. Chen, Z. Luo, X. Chen and F. Kang, Micro Nano Lett., 2017, 12, 27-29.

14 S. Makhluf, R. Dror, Y. Nitzan, Y. Abramovich, R. Jelinek and A. Gedanken, Adv. Funct. Mater., 2005, 15, 1708-1715.

15 A. Kumar and J. Kumar, J. Phys. Chem. Solids, 2008, 69, 27642772 .

16 Z.-Y. Jiang, Q. Kuang, Z.-X. Xie and L.-S. Zheng, Adv. Funct. Mater., 2010, 20, 3634-3645.

17 Z. Kake, H. Juncheng, K. Christian and R. Ryan, Angew. Chem., 2006, 118, 7435-7439.

18 J. Chen, S. Tian, J. Lu and Y. Xiong, Appl. Catal., A, 2015, 506, 118-125.

19 Y.-j. Hao, B. Liu, L.-g. Tian, F.-t. Li, J. Ren, S.-j. Liu, Y. Liu, J. Zhao and X.-j. Wang, ACS Appl. Mater. Interfaces, 2017, 9, 12687-12693.

20 T. Xu, X. Zhou, Z. Jiang, Q. Kuang, Z. Xie and L. Zheng, Cryst. Growth Des., 2009, 9, 192-196.

21 R. Hacquart and J. Jupille, Chem. Phys. Lett., 2007, 439, 9194.

22 M. D. Susman, H. N. Pham, A. K. Datye, S. Chinta and J. D. Rimer, Chem. Mater., 2018, 30, 2641-2650. 
23 Y. Yang, L. Dang, M. J. Shearer, H. Sheng, W. Li, J. Chen, P. Xiao, Y. Zhang, R. J. Hamers and S. Jin, Adv. Energy Mater., 2018, 8, 1703189.

24 Y. Zou, X. Wang, F. Wu, S. Yu, Y. Hu, W. Song, Y. Liu, H. Wang, T. Hayat and X. Wang, ACS Sustainable Chem. Eng., 2017, 5, 1173-1185.

25 G. Cabailh, R. Lazzari, H. Cruguel, J. Jupille, L. Savio, M. Smerieri, A. Orzelli, L. Vattuone and M. Rocca, J. Phys. Chem. A, 2011, 115, 7161-7168.

26 Y. H. Li, Z. K. Luan, X. Xiao, X. W. Zhou, C. L. Xu, D. H. Wu and B. Q. Wei, Adsorpt. Sci. Technol., 2003, 21, 475-485.

27 E. N. E. Qada, S. J. Allen and G. M. Walker, Ind. Eng. Chem. Res., 2006, 45, 6044-6049.

28 D. J. Malik, V. Strelko, M. Streat and A. M. Puziy, Water Res., 2002, 36, 1527-1538.

$29 \mathrm{~J} . \mathrm{Hu}, \mathrm{Z}$. Song, L. Chen, H. Yang, J. Li and R. Richards, J. Chem. Eng. Data, 2010, 55, 3742-3748.

30 W. Yao, S. Yu, J. Wang, Y. Zou, S. Lu, Y. Ai, N. S. Alharbi, A. Alsaedi, T. Hayat and X. Wang, Chem. Eng. J., 2017, 307, 476-486.
31 W. Peng, J. Li, B. Chen, W. Ning, G. Luo and W. Fei, Catal. Commun., 2016, 74, 39-42.

32 V. K. Lazarov, Z. Cai, K. Yoshida, K. H. Zhang, M. Weinert, K. S. Ziemer and P. J. Hasnip, Phys. Rev. Lett., 2011, 107, 056101.

33 J. Hu, K. Zhu, L. Chen, C. Kübel and R. Richards, J. Phys. Chem. C, 2007, 111, 12038-12044.

34 N. Dizge, C. Aydiner, E. Demirbas, M. Kobya and S. Kara, J. Hazard. Mater., 2008, 150, 737-746.

35 Q. Zhou, F. Chen, W. Wu, R. Bu, W. Li and F. Yang, Chem. Eng. J., 2016, 285, 198-206.

36 J. Wang, D. Kang, X. Yu, M. Ge and Y. Chen, Chem. Eng. J., 2015, 264, 506-513.

37 M. Gao, W. Wang, H. Yang and B.-C. Ye, Chem. Eng. J., 2020, 380, 122459.

38 K. El Hassani, B. H. Beakou, D. Kalnina, E. Oukani and A. Anouar, Appl. Clay Sci., 2017, 140, 124-131. 